\title{
Evaluating How the Computer-Supported Collaborative Learning Community Fosters Critical Reflective Practices
}

\author{
Ada W.W. MA \\ Department of Health and Physical Education, \\ The Hong Kong Institute of Education, Hong Kong SAR, China
}

\author{
ama@ied.edu.hk
}

\begin{abstract}
In recent research, little attention has been paid to issues of methodology and analysis methods to evaluate the quality of the collaborative learning community. To address such issues, an attempt is made to adopt the Activity System Model as an analytical framework to examine the relationship between computer supported collaborative learning (CSCL) and critical reflective capabilities. This paper attempts to build an appropriate analysis scheme to reveal the quality of the reflective learning community in the computer supported environment. Data is analysed to examine how interactivity, social presence, and teaching presence have contributed to the mastery of critical reflective capabilities in the CSCL community. Findings revealed that high levels of social interaction and collaboration contributed to the establishment of a community of reflective learners, nurturing a space for promoting critical reflective capabilities through co-creation of new understandings and interpretations for transformative outcomes. Methodological problems encountered will be discussed as well.
\end{abstract}

Keywords: computer-supported collaborative learning community, critical reflective capabilities, Activity System Model, assessment

\section{Introduction}

In recent research, considerable attention has been paid to theoretical debate in the field of computer supported collaborative learning (CSCL). However, little attention has been paid to issues of methodology and analysis methods to evaluate the quality of the CSCL community (De Wever, Schellens, Valcke, \& Van Keer, 2006; Strijbos, Martens, Prins, \& Jochems, 2006) as they have been confronted with a range of problems. One of the problems of researching learning in CSCL environments is perhaps the realisation of the complexity of learning interactions being probed. Analysing how the CSCL community fosters critical reflective practices presents a further challenge.

Material published as part of this publication, either on-line or in print, is copyrighted by the Informing Science Institute. Permission to make digital or paper copy of part or all of these works for personal or classroom use is granted without fee provided that the copies are not made or distributed for profit or commercial advantage AND that copies 1) bear this notice in full and 2) give the full citation on the first page. It is permissible to abstract these works so long as credit is given. To copy in all other cases or to republish or to post on a server or to redistribute to lists requires specific permission and payment of a fee. Contact Publisher@InformingScience.org to request redistribution permission.
The Activity System Model, based on a sociocultural perspective, is adopted as a framework for analysing the quality of CSCL community in this research project. This paper attempts to build an appropriate analysis scheme to reveal the quality of reflective learning community in the computer supported environment. Data is analysed to examine how interactivity, social presence and teaching 
presence have contributed to the mastery of critical reflective capabilities in the CSCL community.

\section{Literature Review}

\section{Concept of Activity Theory}

Activity theory originates from the ideas of Vygotsky with the concept of activity as the most important focus. Leont'ev (1978), a follower of Vygotsky, stressed that activity is also socially mediated: consciousness and meaning are always formed in a joint, collective activity. As a result, the unit of analysis in studying human mediated activity is an activity system. It involves a community of actors who have a common object of activity (Cole \& Engeström, 1993;

Engeström, 1987). In the activity system model, social mediatedness is characterised by a division of labour and rules mediating the interaction between the individuals in the activity system. The collective activity system as a unit of analysis connects the psychological, cultural and institutional perspective to analysis. The study of activity ceases to be psychology of an individual but instead focuses on the interaction between an individual, systems of artefacts and other individuals in a historically developing institutional setting.

\section{Activity System Model as a Framework for Analysing the Quality of CSCL Community}

Activity Theory provides educators with a practical and holistic approach to the evaluation of a CSCL community (Hew \& Cheung, 2003). To make the content analysis valid, there should be a concrete link between the analysis categories and the theoretical framework. Without a theoretical model of the collaborative learning process it is impossible to identify empirical indicators that will form the basis of a coding instrument as a standard against which to evaluate whether effective learning is occurring in the online discussions (De Wever et al., 2006). The activity system model (Engeström, 1987) is useful for bringing together a wide range of information about the factors that impact on the activity. Some of the significant ideas are shown in Figure 1.

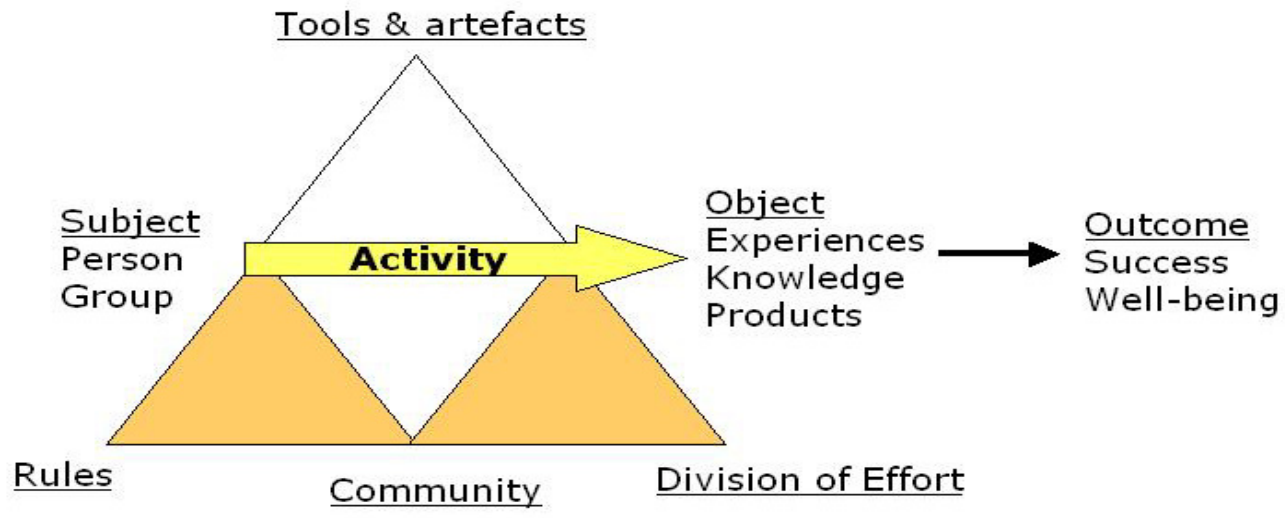

Figure 1 Processes within an activity (Engeström, 1987)

In this study, within the activity system, a team of people including peer learners and facilitators working together as a collaborative group can be seen as a basic unit (subject) of an activity, in which the group members are mainly mediated by the asynchronous discussion forum of the Blackboard Learning System $\mathrm{ML}^{\odot}$ (tool) to engage in a project work on fashion consumerism 
(object) with other members in construction of knowledge or skills. In the process of knowledge construction, the group functions as a community of learners operating under explicit and implicit rules of working together (project collaboration, submission of assignments or assignment criteria), governed through some form of division of labour (roles such as expert-learner or modellingmirroring agent) played by various members of the CSCL community in order to create a meaningful outcome. At the core of the activity system, learning takes place through a dialectic interaction between subject, community and object. Such transactional process is congruent with the social construction of knowledge (Hung \& Wong, 2000).

\section{Evaluation Questions}

Understanding the CSCL process in light of the activity system model, it is possible to identify useful and meaningful indicators to evaluate whether or not effective learning is taking place in the technology-enhanced environment. By considering the various triads of nodes taken from Figure 1, possible structures such as subject-community-object triad, subject-community-roles triad and subject-community-tool triad can be established for analysis.

\section{1). Subject-community-object Triad}

To illuminate how individuals challenge the taken-for-granted assumptions in the moral and ethical contexts and empower themselves to take social actions to cause a change as a result of social interaction and critical reflective discourse within the group, evaluation questions on interactivity and reflective presence are addressed as follows.

When conducting their CSCL activities:

- What is the level of participation among the subjects?

- Have social inquiry approaches being employed in the CSCL environment demonstrated evidence of reflective practice and do they make the reflective processes transparent? and

- To what extent does the construction of a community of reflective learners contribute to the fostering of critical reflection?

\section{2). Subject-community-roles Triad}

To gain insight into what impedes the development of quality social interactions, evaluation questions on social and teaching presence are addressed as follows.

When CSCL activities are taking place:

- Are there any forms of affective communication to yield insight on the psychological state of learners?

- What kinds of feedback are available to yield insight on how the team spirit, mutual trust and openness are promoted?

- Does social presence support the reflective and affective objectives, making the peer debate and challenges appealing and intrinsically rewarding? and

- What is the role played by the facilitator which has affected students' interaction and reflective thinking?

\section{3). Subject-community-tool Triad}

To examine how computer supported environments enhance the collaborative reflective dialogue and formation of a reflective learning community, evaluation questions are addressed as follows. 
When CSCL activities are taking place:

- What are the distinct goals of the communication modes of asynchronous settings?

- How do technical factors hinder or enhance participation and social reflection?

\section{Proposed Content Analysis Scheme for the Study}

The content analysis scheme proposed for this study is based on the activity system model of Engeström (1987) in which the analytical framework of the subject-community-object triad, the subject-community-roles triad and the subject-community-tool triad will investigate the interrelationship among the interactivity, reflective presence, social presence and teaching presence within a CSCL community. A combination of instruments was built to reflect a complete and meaningful picture of the CSCL community. Each instrument adopted has its own value and focuses attention on different aspects of the learners' involvement and reflective thinking as evidenced in the online community. The content analysis scheme comprising four different instruments based on four perspectives is detailed in table 1 as follows.

Table 1. Proposed content analysis scheme for the study

\begin{tabular}{lll}
\hline Instruments adopted & Aspect to be evaluated & Unit of analysis \\
\hline Henri (participative presence) (1992) & Level and intensity of participation & Usage statistics \\
\hline $\begin{array}{l}\text { Self-devised instrument with adoption of } \\
\text { the social inquiry model originating from } \\
\text { Habermas's (1981) critical theory }\end{array}$ & $\begin{array}{l}\text { Reflective presence- } \\
\text { process of social reflection; } \\
\text { social co-creation of new knowledge for } \\
\text { transformative actions }\end{array}$ & Message unit \\
\hline Rourke et al. (1999) & Social presence & Message unit \\
\hline Anderson et al. (2001) & Teaching presence & Message unit \\
\hline
\end{tabular}

To study the way learners of the CSCL community negotiate meanings and construct new critical knowledge for liberation, and to capture the progression of reflective thinking processes as they are reflected at different phases of social interaction and debate, attempts are made to employ the social inquiry model based on Habermas' (1981) critical social theory as the analysis instrument. This model provides a more holistic view of reflective flow as it allows the learners to go through the processes of critical reflection including identification of the assumptions governing the actions, locating the historical and cultural origins of the assumption, questioning the meaning of the assumptions, uncovering the meanings that are embedded in and negotiated through written language or communicative dialogue; followed by developing alternative ways for acting. It is the most appropriate model used in the CSCL context with a focus on social interaction for peer debate and critique which serves as the vehicle for rational argumentation and creation of new knowledge for transformative actions. Indicators categorised are not only within the main elements of a community of inquiry such that coherence and meaning are apparent, they also make the dialectic inquiry involving a back-and-forth exchange among learners through social collegial debate transparent.

\section{Unit of Analysis}

To conduct the content analysis, a unit of analysis had to be devised. The use of a message unit which allowed for the possibility that a single message might exhibit characteristics of more than one category was utilised as the unit of analysis in the online learning community. This procedure proved to have a number of advantages for investigation. First, the number of coding decisions was predetermined for the coders. This was useful for alerting coders to the need to make a deci- 
sion and provide a denominator for calculating reliability. Second, the system was quickly implemented and did not require coders to determine the number or the exact text length of indicators present per unit of analysis. Third, totals for each category were meaningfully expressed by reporting the percentage of total postings that contained each of the categories (Anderson et al., 2001).

\section{Content Analysis Procedures}

The actual analysis of the postings was carried out into two parts in this study. The online postings were first studied at the message level, and categories according to different perspectives to be evaluated were chosen as the appropriate units of analysis. The second part involved the use of the content analysis scheme with various chosen instruments on the identified units of analysis. The intragroup reflective paper, with the findings of the online intra and intergroup debate as the base, was submitted as a written report. The written reflective report was first studied at the report level and evidence of reflective processes and practices (transformative proposals) were then identified for evaluation. To ensure intercoder percentage agreement, the data were coded by the facilitator and the research assistant. Percent agreement was arrived at $90 \%$ on the unit of analysis, $96 \%$ on nature of participation, $82 \%$ and $85 \%$ on phases of social construction of new interpretations for transformative actions in intra and intergroup debate respectively, $80 \%$ and $99 \%$ on categories of social and teaching presence respectively.

\section{Data Analysis and Findings}

Five groups of 4-6 students were involved in a 5 week project, challenging the taken-for-granted assumptions that had perpetuated injustices and inequalities in fashion advertisements. Students were required to conduct intragroup argumentation online on their selected sets of fashion advertisements using the prompt guides during the first 3 weeks of the project period. The final PowerPoint presentation for inter-group debate was to be submitted in the 4th and 5th weeks. Intragroups were encouraged to have online discussions with their group members during the process, and they had to submit reflective journals weekly. The instructor took the role of facilitator during the process and provided overall feedback on learners' participation in the 5th week. Both intraand intergroup messages, as well as written reflective reports, were collected and analysed for this study. Out of the five groups of students, students from Groups A, B, E and F were the mixed mode learners who were in-service teachers, while students of Group C (formerly members of Group C and Group D were merged as one group to provide more human resource inputs) were full-time learners.

\section{Interactivity}

The level and intensity of participation was analysed in the form of usage statistics, comprising the number of messages posted, the number of messages per student, and the number of threads and messages per thread. Such rich sources of data are expected to illuminate how collaborative learning conditions are generated and maintained. The intra and intergroup messages were collected and a detailed analysis on interactivity was conducted as follows.

\section{Level of participation: Messages posted}

The participants' level of engagement varied greatly. With reference to Figure 2.1, amongst four groups of mixed-mode student-teachers, Group A posted the most valid messages (162) when compared with Group E and Group C who posted the least (64) over the project period. There were a total of 139 messages contributing to the intergroup discussions. 


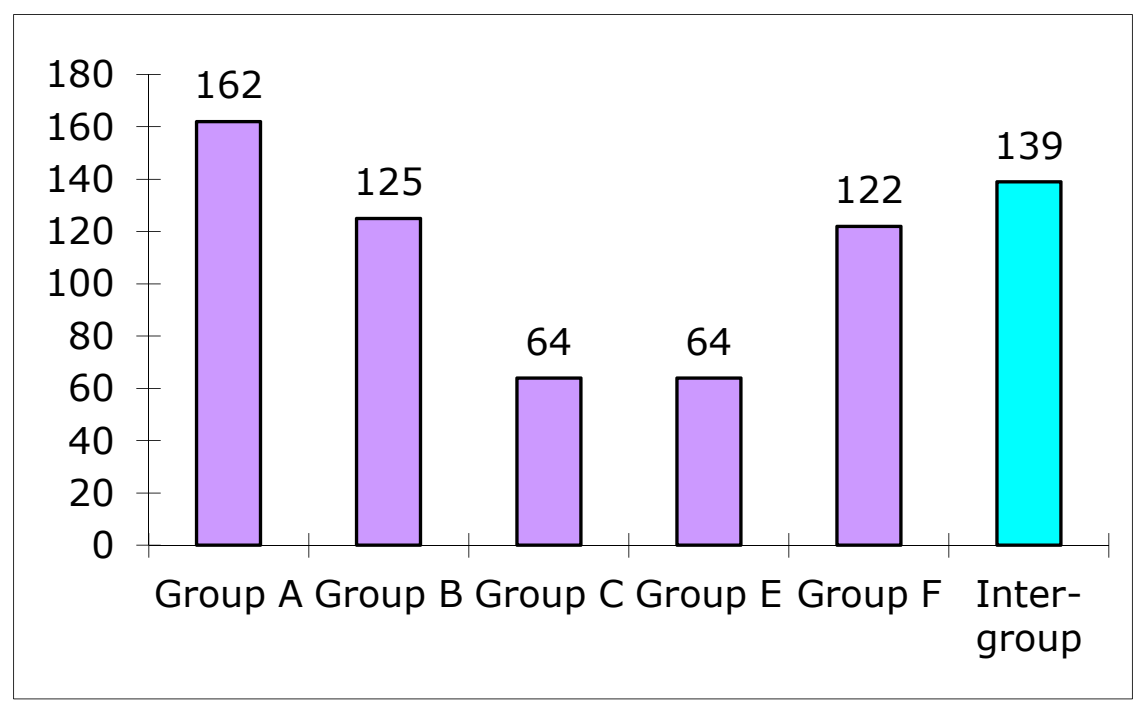

Figure 2.1 Numbers of valid messages posted by Groups A-F

The data reveals how intra-groups might operate quite differently. It was found that learners of Group A and B were actively engaged in the collaborative reflective task and their interaction was rich. Group $\mathrm{C}$ was more passively involved which might be attributed partly to their full-time learner status, where traditionally there was a lot of face to face communication, and partly due to the fact that this group was newly formed from the former Group C and Group D where group cohesion might not have been as established as the other groups.

Figure 2.2 shows the intergroup frequencies of message creation. It was possible to highlight three categories of contribution: (a) about $60 \%$ of the learners posted 1 to 5 messages, (b) $35 \%$ of them posted 6 to 10 messages, and (c) only $5 \%$ posted ten to twenty messages. Student WCW was identified as the most active member because she contributed most both in her Group F and in the intergroup open discussion while student WCT could be viewed as an isolated participant who contributed the least in her Group $\mathrm{C}$ and failed to contribute to the intergroup discussion.

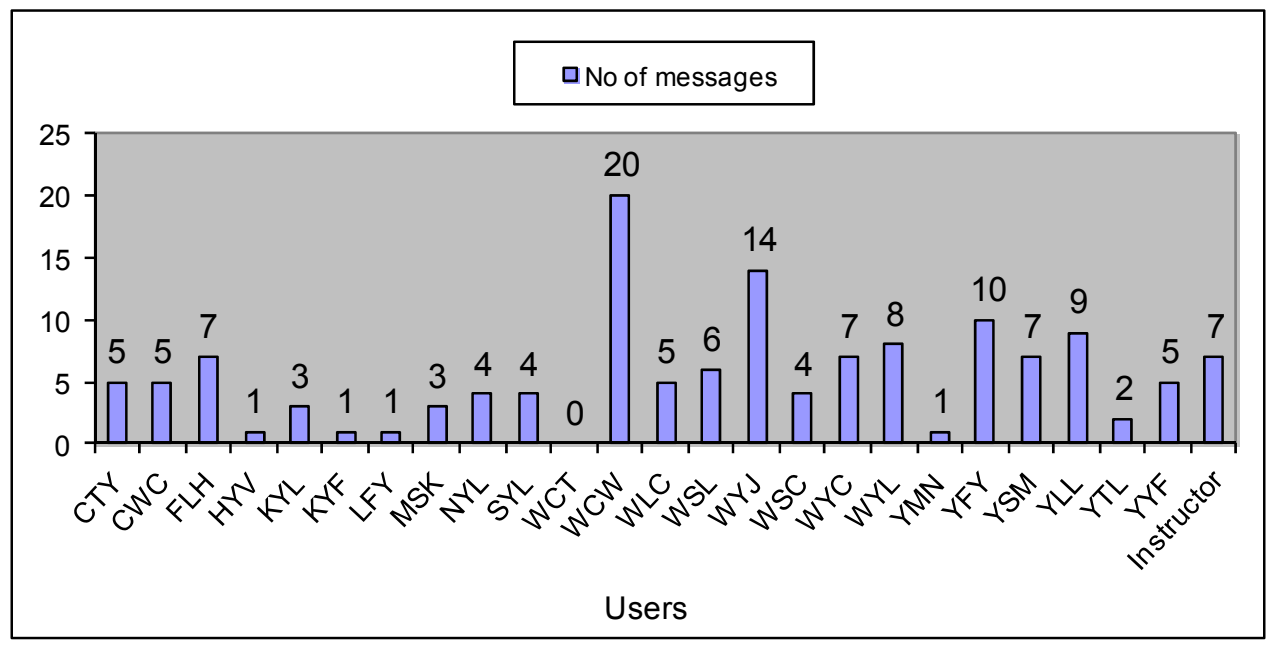

Figure 2.2 Number of messages per user in intergroup discussion

Generally speaking, most of the learners were involved within the intergroup discourse with Group A contributing the most inter-group messages and Group C contributing the least, as shown in Figure 2.3. Further breakdown of their involvement in intergroup debate was displayed 
in Figure 2.4 and 2.5 which revealed that most of the Group A actively participated in open discussion while Group $\mathrm{C}$ was not willing to take an active part.

Interesting data was obtained from students HYV, KYF, LFY and YMN who were found to be relatively active members in their intragroups but were most inactive in the intergroup debate. It suggests that trust might not have been be fully established within the intergroup community and they were not open enough to challenge the views of their peers whom they had did not know. This might be explained by a perception of the intergroup forum as an untrustworthy environment where learners might feel uncomfortable or threatened by open argumentation.

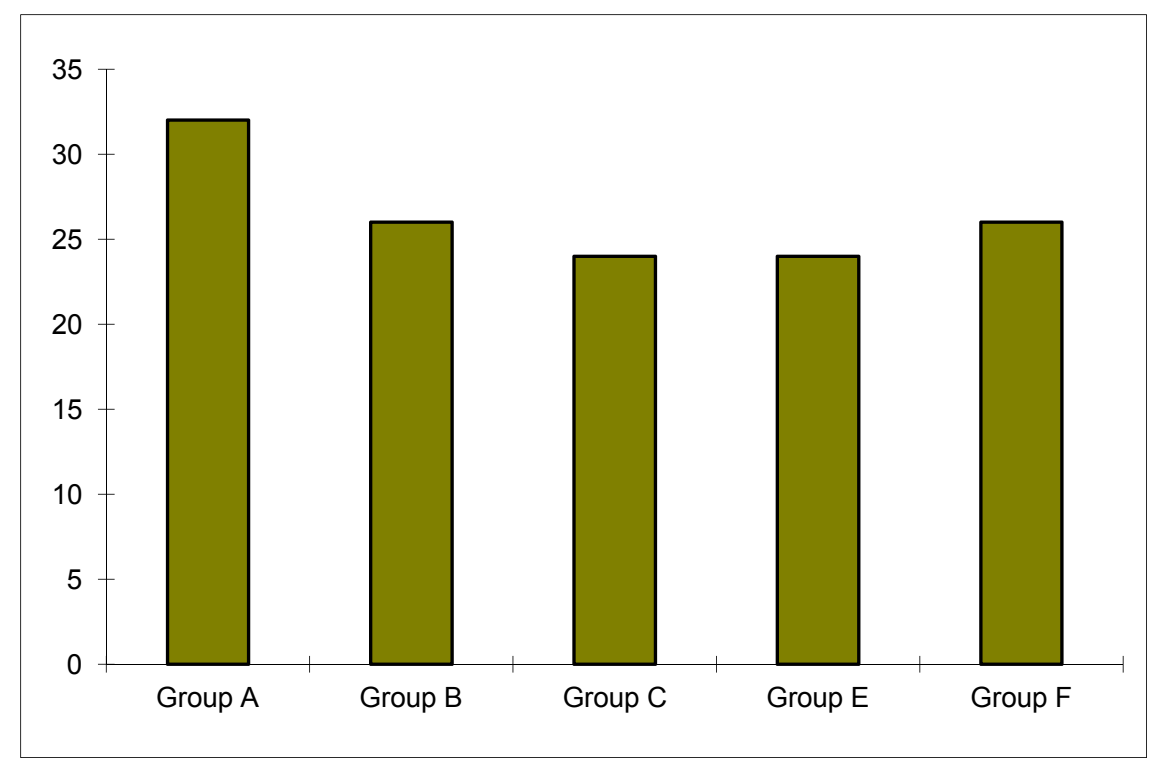

Figure 2.3 Number of intergroup message per group

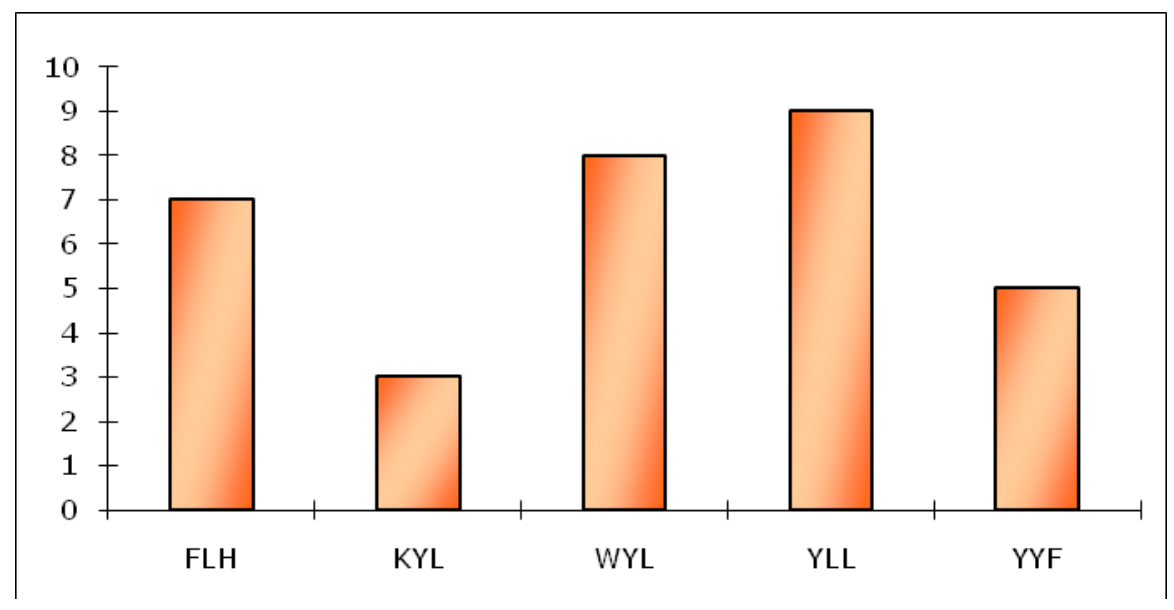

Figure 2.4 Numbers of intergroup messages per user in Group A 


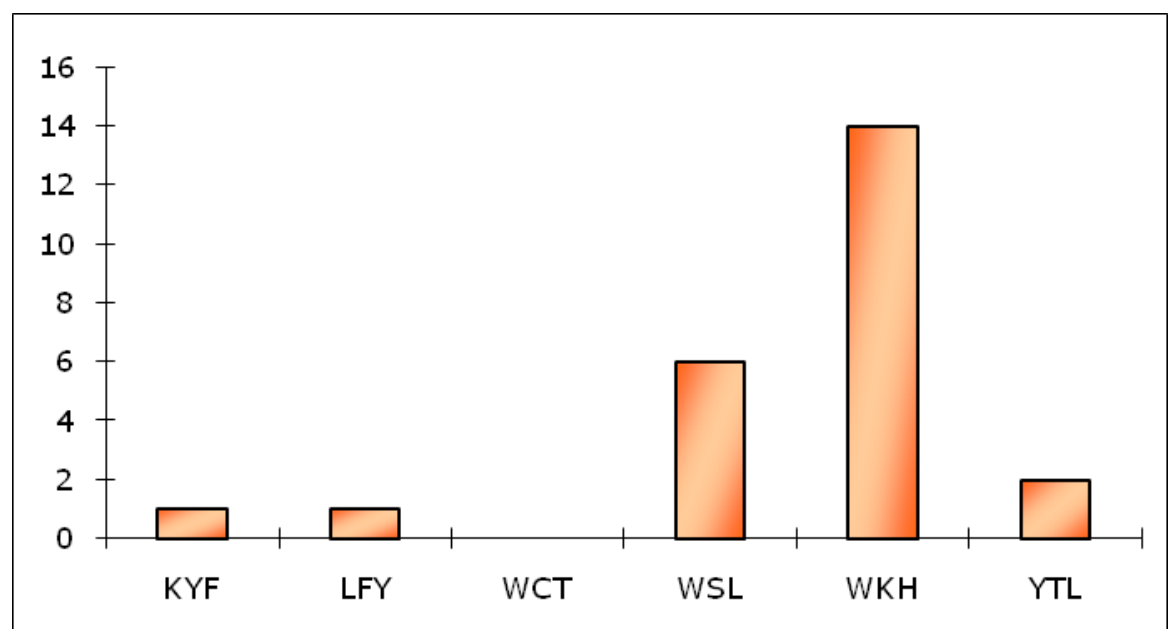

Figure 2.5 Numbers of intergroup messages per user in Group C

\section{Level of participation: Intensity of participation by analyzing threaded messages}

To help better capture and show the patterns of connection among the units of analysis, a visual mapping of all the units is presented in Figure 2.6-2.10 to reveal whether the students were responding and arguing each other's ideas.

\begin{tabular}{|c|c|c|c|c|}
\hline $\begin{array}{l}0 \\
R\end{array}$ & $\begin{array}{l}0 \\
\text { R } \\
\text { R }\end{array}$ & $\frac{O}{R}$ & $\begin{array}{l}\mathrm{O} \\
\mathrm{R}^{\mathrm{R}} \mathrm{R} \\
\mathrm{R}\end{array}$ & $\begin{array}{l}0 \\
\text { R } \\
\text { R } \\
\text { R }\end{array}$ \\
\hline 13 messages & 7 messages & 3 messages & 3 messages & 2 messages \\
\hline$\frac{0}{R}$ & $\frac{0}{R R R}$ & $\frac{O}{R R}$ & $\frac{O}{R R R} \frac{0}{R}$ & $\begin{array}{l}0 \\
\text { Re } \\
\text { Re } \\
\text { Re } \\
\text { R } \\
\text { R }\end{array}$ \\
\hline 2 messages & 1 message & 1 message & 1 message & 1 message \\
\hline 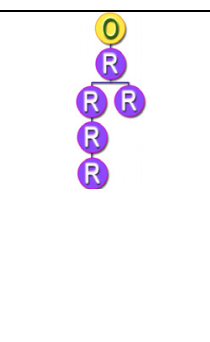 & $\begin{array}{c}0 \\
R \\
R \\
R \\
R \quad R \\
R \quad R\end{array}$ & 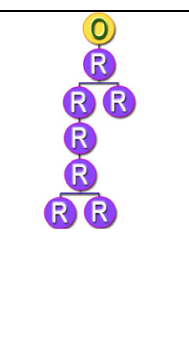 & 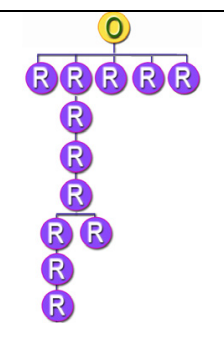 & \\
\hline 1 message & 1 message & 1 message & 1 message & \\
\hline
\end{tabular}

Figure 2.6 Threaded messages generated from postings of Group A

Based on the visual mapping in Figure 2.6, 38 threaded messages were identified from the 162 messages and with $39.5 \%$ being regarded as active threads (a threaded message with 3 to 12 referents, going deeper from level 2 to 7 ), indicating heated discussion was taking place, with ample scaffolding provided among the members. 
Based on the visual mapping in Figure 2.7, in Group B, 24 threaded messages were identified from 125 messages, with $29 \%$ being regarded as active threads (a threaded message with 3 to 8 referents, going deeper from level 2 to 8 ), indicating learners were actively engaged in the discussion, cooperatively assisting each other.

Based on the visual mapping in Figure 2.8, in Group C, 9 threaded messages were identified from 64 messages with $55.5 \%$ of the threaded messages going no deeper than level 1, indicating that the members were not collaborating and each received little input from the peers.

\begin{tabular}{|c|c|c|c|}
\hline Q & $\frac{0}{R}$ & $\frac{0}{\mathrm{R} R \mathrm{R}}$ & $\begin{array}{l}0 \\
R \\
R\end{array}$ \\
\hline 6 messages & 3 messages & 3 messages & 3 messages \\
\hline $\begin{array}{c}0 \\
R \\
R R\end{array}$ & Q & $\begin{array}{c}\mathrm{O} \\
\mathrm{R} R \\
\mathrm{R} R \\
\mathrm{R} R \\
\mathrm{R}\end{array}$ & $\frac{0}{\mathrm{R} R \mathrm{R} R}$ \\
\hline 2 messages & 2 messages & 1 message & 1 message \\
\hline $\begin{array}{c}\mathrm{O} \\
\mathrm{B} R \mathrm{R} \\
\mathrm{R} \\
\mathrm{R}\end{array}$ & \multicolumn{2}{|c|}{ RBRRBR } & $\begin{array}{l}\text { O } \\
\text { R } \\
R \\
R \\
R \\
R \\
R \\
R \\
R \\
R \\
R\end{array}$ \\
\hline 1 message & \multicolumn{2}{|c|}{1 message } & 1 message \\
\hline
\end{tabular}

Figure 2.7 Threaded messages generated from postings of Group B

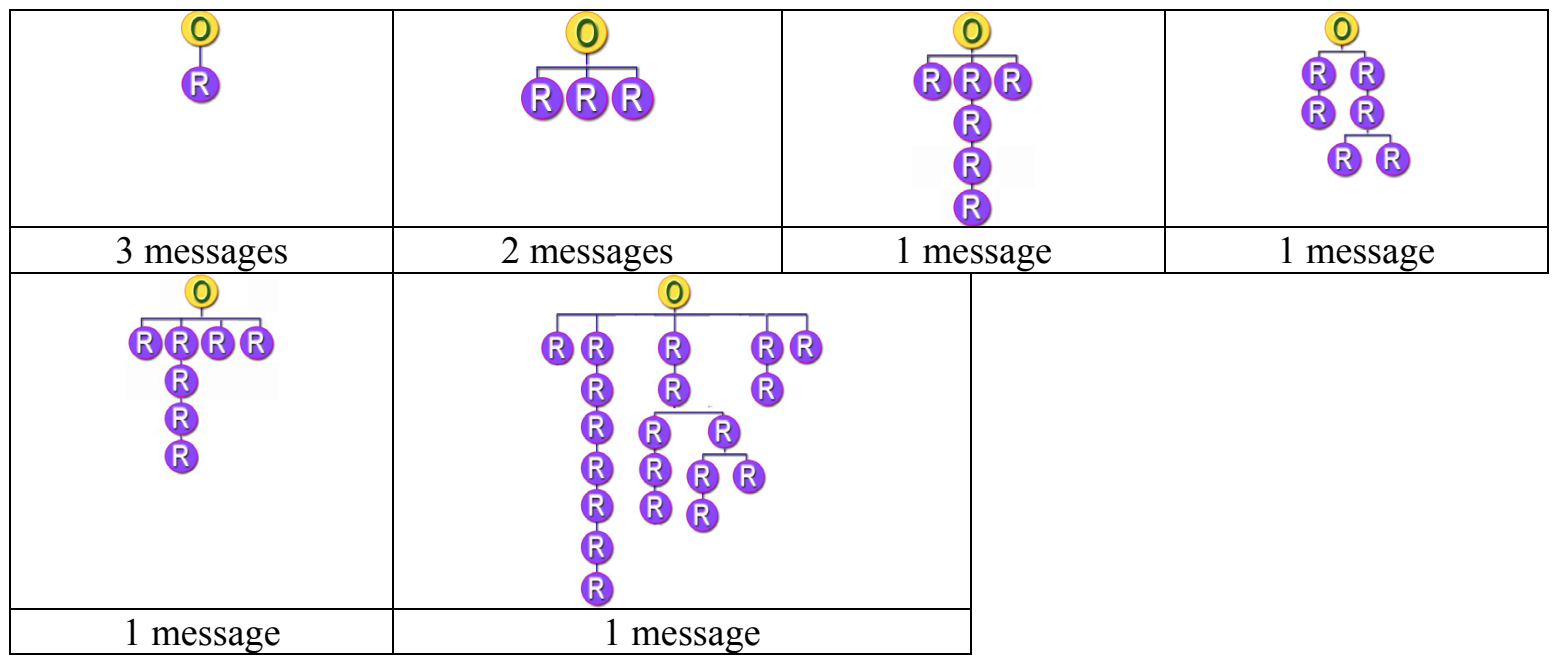

Figure 2.8 Threaded messages generated from postings of Group C

Based on the visual mapping in Figure 2.9, in Group E, 12 threaded messages were identified from 64 messages with $58 \%$ of the threaded messages going no deeper than level 1, indicating that the members were not committed to collaboration. 


\begin{tabular}{|c|c|c|c|c|}
\hline $\begin{array}{l}0 \\
1 \\
R\end{array}$ & $\begin{array}{l}0 \\
R \quad R\end{array}$ & $\begin{array}{c}\mathrm{O}^{\mathrm{P}} \\
\mathrm{R}^{\mathrm{R}} \mathrm{R}\end{array}$ & $\begin{array}{c}\mathrm{O} \\
\mathrm{R} \\
\mathrm{R} R\end{array}$ & $\begin{array}{l}0 \\
R^{R} R \\
R \\
R\end{array}$ \\
\hline 5 messages & 2 messages & 2 messages & 2 messages & 1 message \\
\hline
\end{tabular}

Figure 2.9 Threaded messages generated from postings of Group E

Based on the visual mapping in Figure 2.10, in Group F, 24 threaded messages were identified from 122 messages, with $45 \%$ being regarded as active threads (a threaded message with 3 to 7 referents, going deeper from level 2 to 5), indicating heated discussion was taking place, with ample scaffolding among the members rendered.

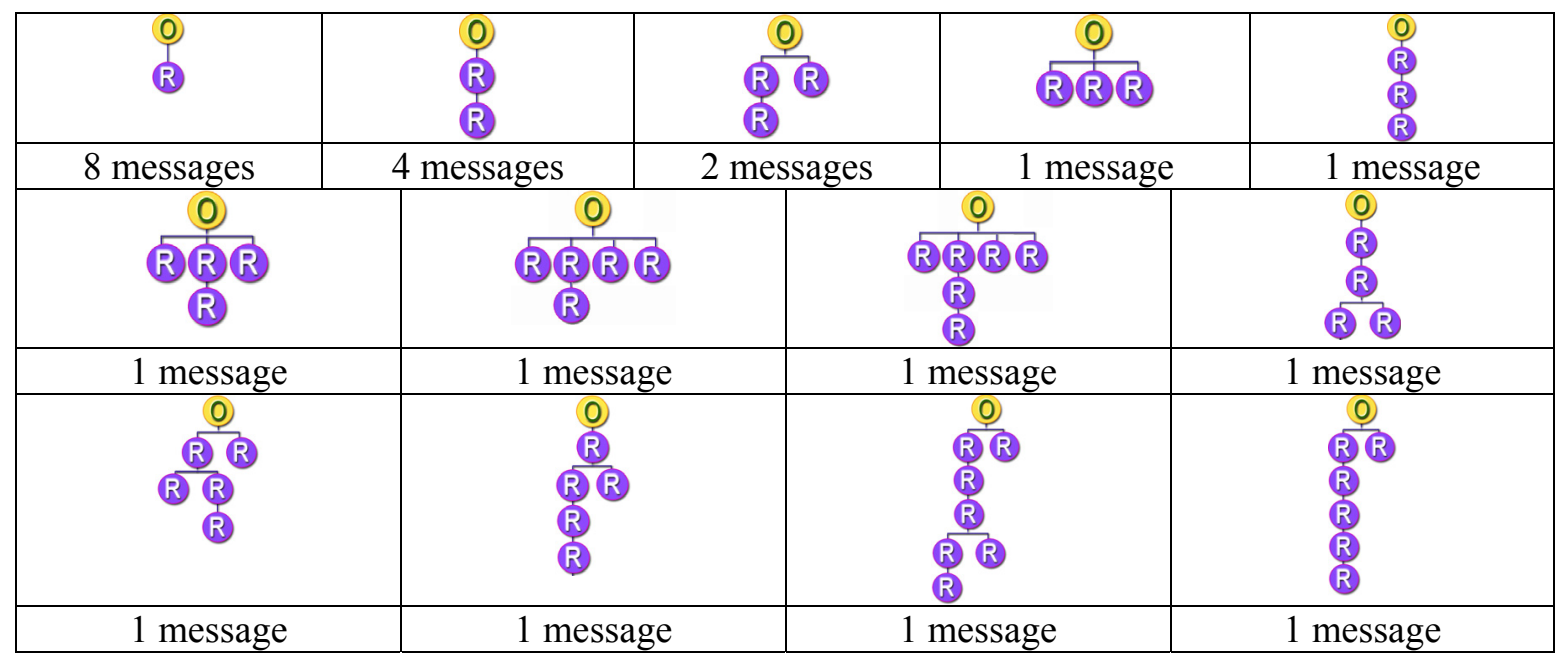

Figure 2.10 Threaded messages generated from postings of Group F

To sum up, engagement of members in the learning community varied significantly. It was found that most participants in Group $\mathrm{C}$ and $\mathrm{E}$ sent new messages in which there were hardly any responses sent in reply. Further, most of the threaded messages identified in Group $\mathrm{C}$ and $\mathrm{E}$ were quite linear and did not show much interaction as more than half of the discussion threads did not go deeper than level 1 . There was the possibility that the learning community was not established in these two groups possibly due to low levels of social interaction and insufficient support being rendered to scaffold learning among the members. In contrast, Group A generated threaded messages with most intensive interaction in which $39.5 \%$ were regarded as active threads. In itself, this feature was evidence of high levels of social interaction and collaboration, contributing to the establishment of a community of learning.

\section{Nature of Participation}

To understand the nature of participation, the messages were classified into four main categories based on Henri's (1992) model, namely: administrative, technical, social, and content as presented in Figure 3.1. For each main category, a message unit might possibly exhibit characteristics of more than one category (Figure 3.2). The findings shown in Figure 3.1 reveal that nearly half of the messages related to content, revealing that the learners' main focus was the discussion relating to their reflective tasks. Group B was the exception with social messages almost twice that of content messages. Group $\mathrm{C}$ received most administrative messages from the facilitator, indicating that they required the most support from the facilitator. Groups A, B and F posted the most technical messages, and their experience with technology was worth attention. Group A and 
B posted a huge amount of social messages accounting for $51.5 \%$ and $54.7 \%$ of their total messages respectively and their impact on establishment of a trustworthy CSCL environment for enhancing interactivity and quality of reflection deserved further investigation.

The analyses conducted on the level, intensity and nature of participation has illuminated interaction patterns among the groups. The next section will discuss in detail how such patterns of interaction contribute to fostering the critical reflective capabilities of learners in terms of levels of reflection and co-creation of reflective knowledge for transformative actions.

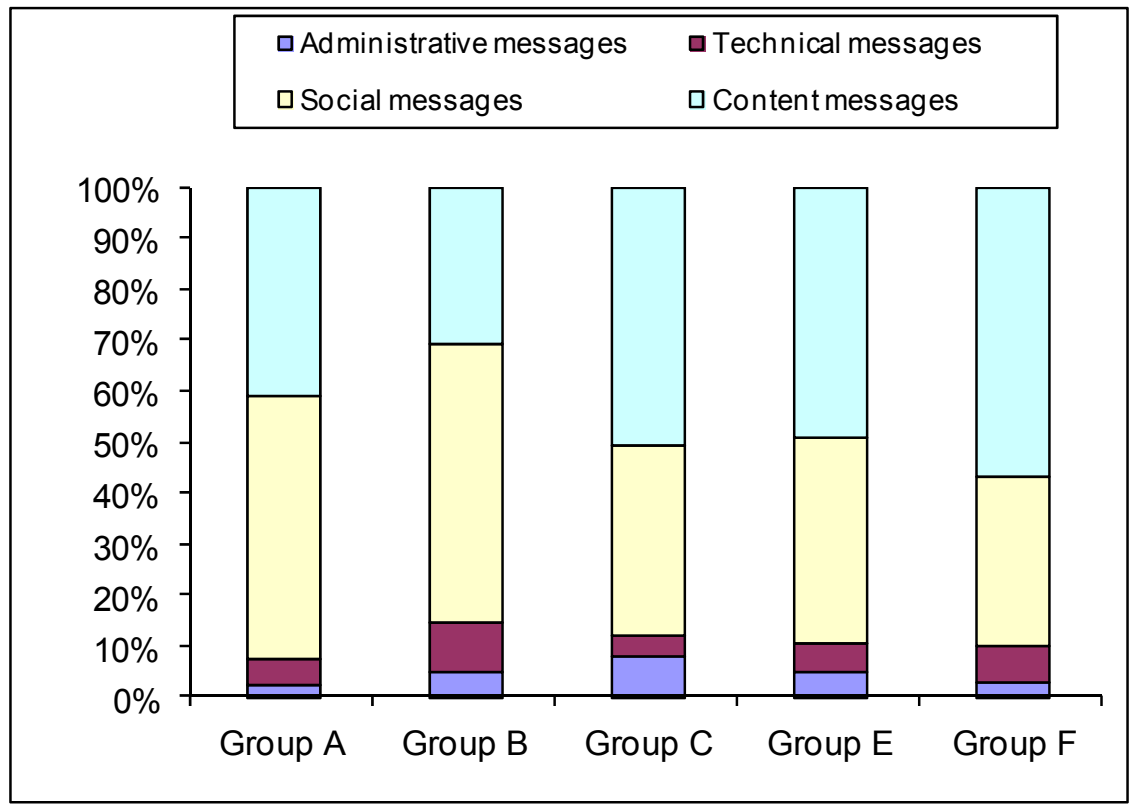

Figure 3.1 Distribution of coded messages showing the nature of participation of Group A-F

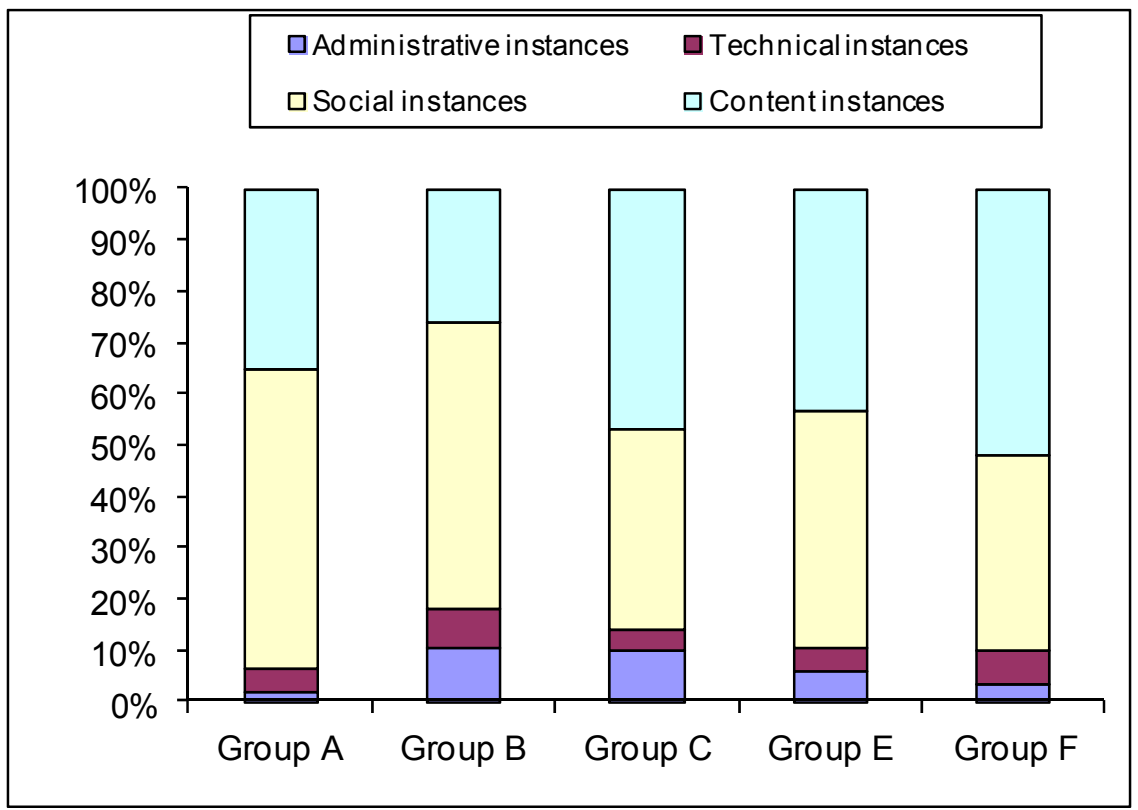

Figure 3.2 Distribution of coded instances showing the nature of participation of Group A-F 


\section{Processes of Reflection}

Three types of data are presented in this section. The first type of data was derived from the intra and intergroup online debate. The second is an analysis of the intragroup's reflective E-journals. The third is a brief summary of the findings elicited from the intra-group's reflective reports. Findings of these data illuminate the quality of critical reflective capabilities among learners in terms of processes of reflection. For detailed description on how to devise analytical framework for determining learners' reflective processes, please refer to the paper titled "Determining learners' reflective levels and processes in a computer supported collaborative learning environment A case study of Fashion Consumerism" (Ma, 2012).

\section{Processes of reflection exhibited in the intra and intergroup online discourse}

To capture the progression of reflective thinking as they were reflected at different phases of social debate, the coded content messages were divided into categories based on social inquiry model originating from Habermas' (1981) critical theory. This model demonstrates the reflective flow and how the social interaction has served as the vehicle for peer argumentation and creation of new knowledge for self-empowerment. With reference to the design of the collaborative reflective tasks, it was anticipated that Phase I-III of the social inquiry process would be evident in the online intra and intergroup debate (Ma, 2012). In this regard, the coded content messages initially distinguished the first three phases of reflective thinking, from Phase I to Phase III, indicating progress from the initial to higher reflective functions and revealing how learners' rational argumentations contributed to new understandings and appreciations:
Phase I: $\quad$ Discussion and initial reaction to practices and beliefs
Phase II: $\quad$ Exploration of practices and beliefs
Phase III: Considering issues of ethics and justice

As the design of the collaborative reflective tasks required learners to present the outcome of intragroup discourse for intergroup debate, some messages were posted to organise the tasks and to conduct discussions on production of the PowerPoint slides for presentation. These messages did not fall into any of the Phases mentioned above. They were classified as 'Others'.

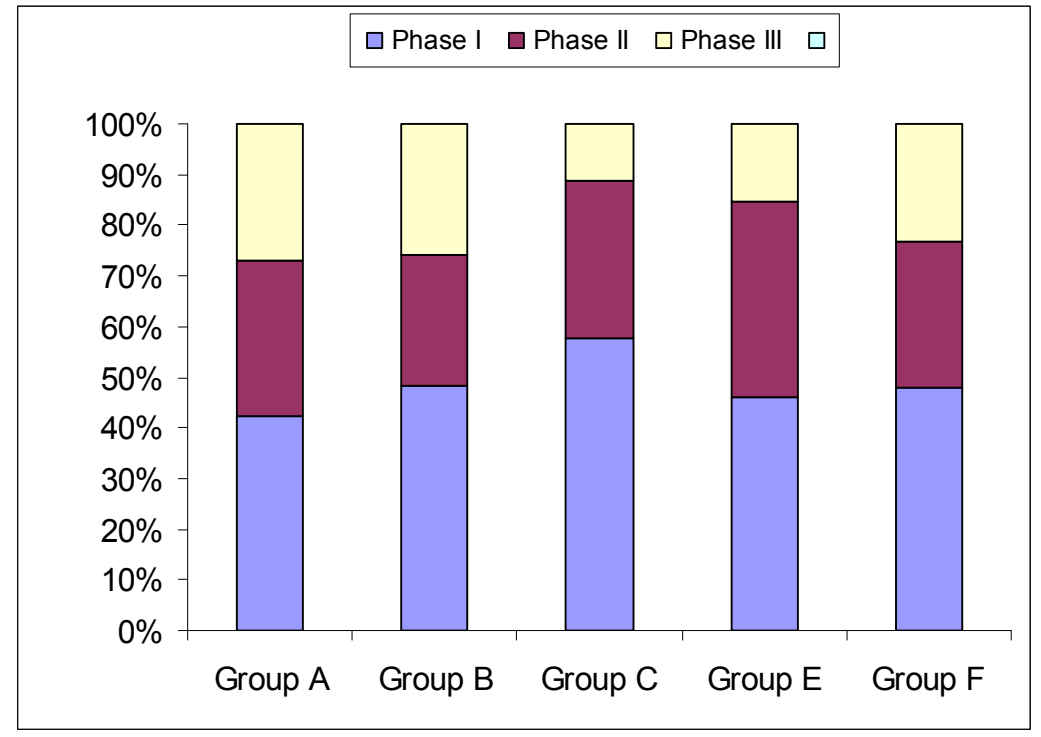

Figure 3.3 Summary of analysis of content messages at each phase of the reflective thinking process for intragroup A-F 
Data analysed in Figure 3.3 suggests some clear patterns over the three phases of the reflective processes in the intragroup discussion. Most of the reflective discourse (42\%-58\%) among the intragroup members remained in the phase of initial discussion and reaction to practices and beliefs (Phase I). This was somewhat expected as this phase of reflective process would provide the platform for further exploration of human action and behaviour as a consequence of external and internal constraints. Phase II comprised $29 \%-39 \%$ of statements exploring the taken-for-granted beliefs and practices. Phase III comprised $11 \%-27 \%$ of the reflective discourse which was evidence of a considerable amount of moral and ethical consideration of issues, leading to the transformation of personal, social or other situations in their later stage of reflective processes.

Amongst all groups, Group A demonstrated that they were the most reflectively engaged with a high quality of social interactions that occurred in the intragroup discussion forum, with as high as $26.9 \%$ of the statements related to moral and ethical consideration of issues, which was a strong indicator of deep reflective processes taking place. Group C, on the other hand, was found to be the least likely (11.1\% of Phase III statements) to turn the spotlight of questioning on their underlying beliefs and assumptions publicly. The following excerpt from Group A is an example of students' collaborative reflective thinking processes in the CSCL environment.

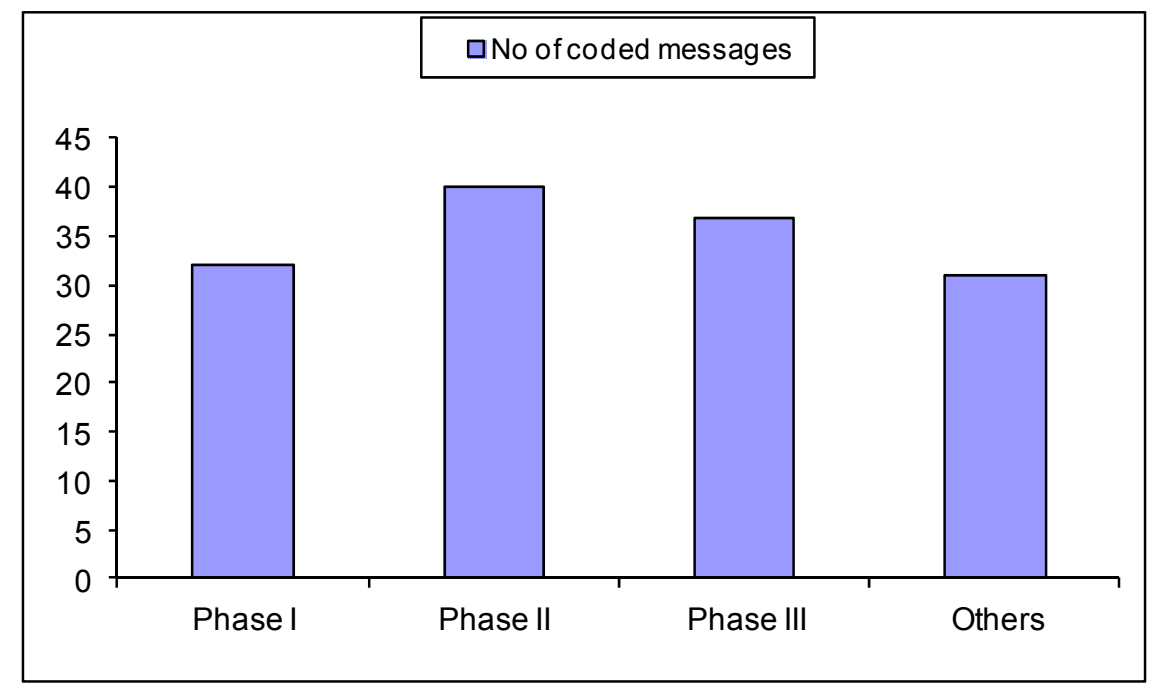

\section{Figure 3.4 Summary of analysis of content messages at each phase of reflective thinking process for intergroups A-F}

Data analysed in Figure 3.4 demonstrated that all students were able to engage actively in the intergroup debate with satisfactory performance over the three phases of reflective processes. It was found that as high as $33.9 \%$ of statements related to moral and ethical questioning of the practices and beliefs, much higher than those being exhibited in the intragroup discourse (11\%-27\%) which suggested that more instances of deep reflection were promoted by interpeer critique and debate in the CSCL environment that fostered equal participation, open communication, and greater diversities of perspectives.

\section{Proposed emancipatory actions summarised from the intragroup written reflective reports}

With reference to the design of collaborative reflective tasks, intra and intergroup online debate formed the base for learners' extensive argumentation for emancipatory actions which were submitted as a written reflective report. In this case, contents of the reflective reports were examined 
for the last three phases of reflective thinking, from Phase IV to Phase VI, indicating their decisions if actions would be taken to cause a change to the unjust practices:
Phase IV:
Alternative value positions
Phase V:
Adoption and defense of a value position
Phase VI:
Action planning to redress inequitable practice

All of the submitted reports had attempted to clarify the issues from the outcomes of the online debate. Further exploration started with alternative value positions (teenage reader of fashion magazine, parents, fashion retailer, fashion designers, fashion advertising agents, magazine editor/owner) which gave rise to proposed actions for transformation. A brief summary on their proposals to redress practices in society with respect to inappropriate images in fashion magazines are as follows:

- All groups proposed to incorporate a "social inquiry approach" as a strategy in classroom teaching with issues concerning the well-being of the individuals, family and society being raised for reflective argumentation. All groups expressed that it was a brand new and meaningful experience for critical reflection with social inquiry and found it very useful and powerful. They believed that the injustice practices with negative impacts on some groups of people in society still continued unchallenged and was mainly due to a lack of opportunity, in the existing curricula for students to foster their critical reflective capabilities.

- The critical self-reflective process of members of all groups found that low self-esteem in individuals was the strong internal factor which allowed the taken-for-granted assumptions to work within them. They proposed adding extra-curricular activities in their schools to cater for diversified needs of students to promote their positive self-images and self-confidence. One group proposed a very interesting action for transformation, that is, to run a mini boutique selling apparel of bigger sizing. They provided an alternative definition of beauty, leading to a greater degree of self-acceptance.

- Some groups went further and suggested that a workshop on uncovering the sociopsychology of fashion advertising should be conducted for teachers, parents and students to enhance their understandings of how the biased ideologies came with culture, socialisation and personal life history, in an effort to put a stop to the unconscious negotiation of distorted and invalid beliefs.

- A few groups proposed a more radical social change by writing a letter to the political party concerned to plea for a control over fashion advertising and to ask for a more serious penalty for immoral and unethical practices in the media.

It was encouraging to witness the critical reflective thinking processes exhibited in the intra and intergroup online debate in which some transformative action plans were proposed to challenge the inappropriate fashion images portrayed in fashion magazines, potentially having a profound effect on their professional practices as educators in secondary school settings.

\section{Social Presence}

The message bodies being classified as social were further divided into three categories based on the Rourke, Anderson, Garrison, \& Archer (1999) model, in which the responses are categorised as interactive, cohesive or affective. The possibility that a single message might exhibit characteristics of more than one category was allowed. A total of 465 coded instances out of 369 social messages were identified and analysed to reveal the level of social presence to support social reflection in a CSCL community. A selection of instances illustrating the concept of social presence manifested in the transcripts is shown below. 
- We come to the same understanding regarding the hidden messages found in these fashion advertisements. Perhaps we can concentrate on analyzing how the fashion merchandisers portray such kinds of messages. (GB-9-WLC) - Interactive response

- As what Ann perceives, I think the images portrayed by the fashion models in these advertisements are far from reality. (GF-40-YMN)- Cohesive response

- I think the sense of responsibility and involvement of our group is extremely good. A big 'tick' should be there for all of us. (GA-43-FLH)-Affective response

It was found that $38 \%-58 \%$ of the coded instances fell into the category of social nature of participation and such high scores indicated that the CSCL environment was collegial and trustworthy in which participants had a sense of affiliation with each other and a sense of solidarity with the group. Amongst all groups, Group A posted the highest number of social messages while Group C posted the least as shown in Figure 4.

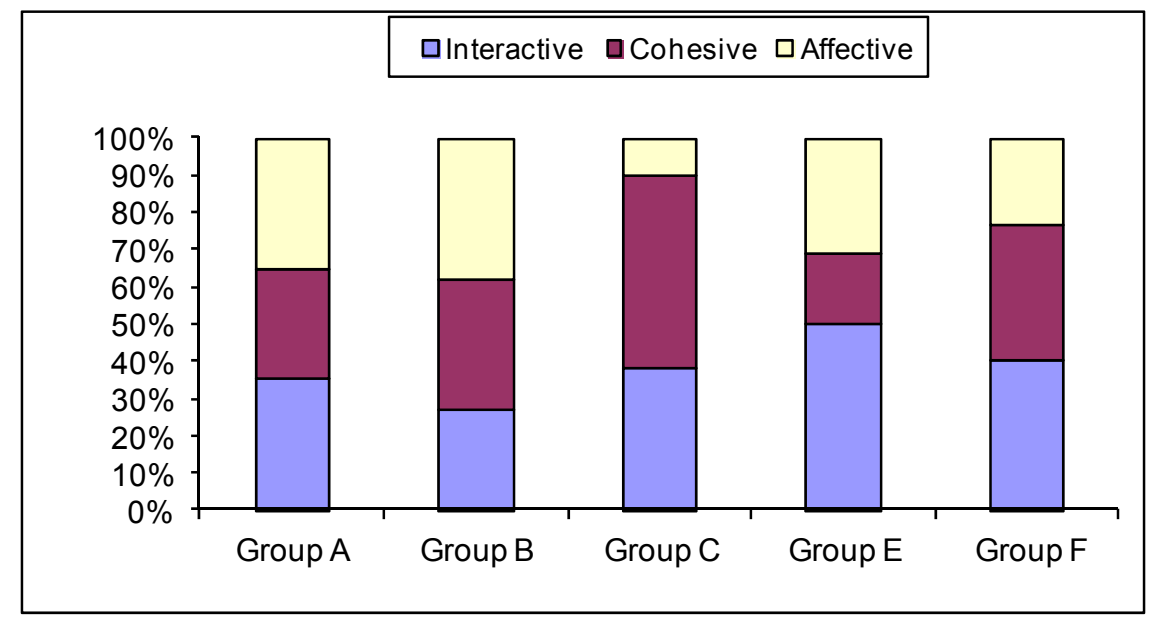

Figure 4 Summary of analysis of social instances for Groups A-F

A further breakdown of the social instances indicated that around $27 \%-50 \%$ of instances of interactive responses were identified, indicating their willingness to communicate mutual attention and awareness. The instances of cohesive responses of Group A, B and C was as high as $30 \%$, $35 \%$ and $36.5 \%$ respectively which revealed that they had built and sustained a sense of group commitment. Group cohesion was found not to be strongly established in Group E with the lowest instances of cohesive responses as $19 \%$. Group C, on the other hand, had posted as low as $10 \%$ of affective responses, indicating that they might have to collaborate in an environment with insufficient interpersonal support and encouragement being rendered to their peers.

\section{Teaching Presence}

The messages that were coded as administrative were further divided into three categories based on the work of Anderson et al. (2001), in which the moderation role as designers of the educational experience, co-creator of a social environment and subject matter expert were identified. A selection of instances illustrating the concept of teaching presence manifested in the transcripts is shown below.

Facilitator taking the role as designers of the educational experience:

I have received the second week reflective journal by email but I fail to get hold of it in the digital drop box. Did you encounter any difficulties in using the drop box? (GA-65) 
Facilitator taking the role as co-creator of a social environment:

It's encouraging to witness that your group has collaborated very well with lots of meaningful interactions. Critical thinking is also promoted within the group discussion. Well done!

$(G F-4)$

\section{Facilitator taking the role as subject matter expert:}

It would be useful to uncover the hidden messages/values that have been portrayed in the advertisement if every member of the group could share some of your personal experience re viewing the advertisement before and after peer discussion and critique. (GF-5)

In this study, it should be noted that the facilitator made fewer postings than the groups with 31 messages ( $6 \%$ of total coded messages). This shows that the facilitator was undertaking his or her role in shaping and maintaining collaborative reflective discourse. Group A received the least support from the facilitator with $12.2 \%$ instances of teaching presence while Group B and C received the most $(29.2 \%$ and $24.3 \%$ respectively).

A further breakdown of the administrative messages as shown in Figure 5 indicates that the facilitator had taken the major moderator role as the co-creator of a social environment who encouraged learners to undertake collaborative reflection. Amongst all groups, Group B and Group C received the most support from the subject matter expert (50\%) in the process of co-creation of new understandings and reflective knowledge.

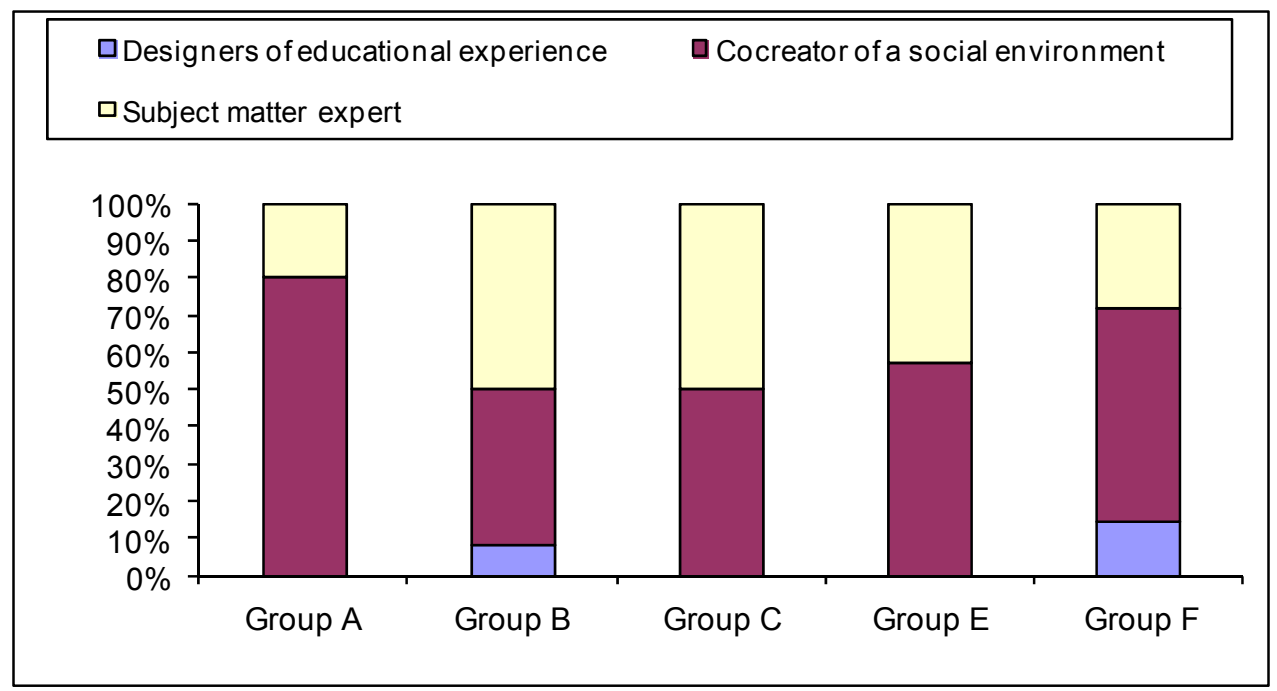

Figure 5 Summary of analysis of types of moderation intervention for Groups A-F

\section{Technical Factors}

The messages coded as technical were then divided into two categories; either as 'hindering' or 'enhancing' students' social reflection using the platform as shown in Figure 6. Findings clearly indicated that most of the learners felt overwhelmingly comfortable with collaborating in the computer supported environment and could work within with ease. A selection of messages illustrating the technical factors that enhanced students' participation is shown as follows:

- Ms Ma, I follow the instruction that you have taught me how to hand in the assignment in the previous module (Textile Studies) and I can manage it easily this time. (GB-67-YST)

- I've sent our reflective journal through the digital drop-box to Miss Ma yesterday. Today, I could see her prompt reply and encouraging comments. I'm thrived. (GB-114-MSK) 
- Even though I am in the State, I can join in the e-learn forum via the Internet. I can communicate with you through email as well (GF-16-HYV)

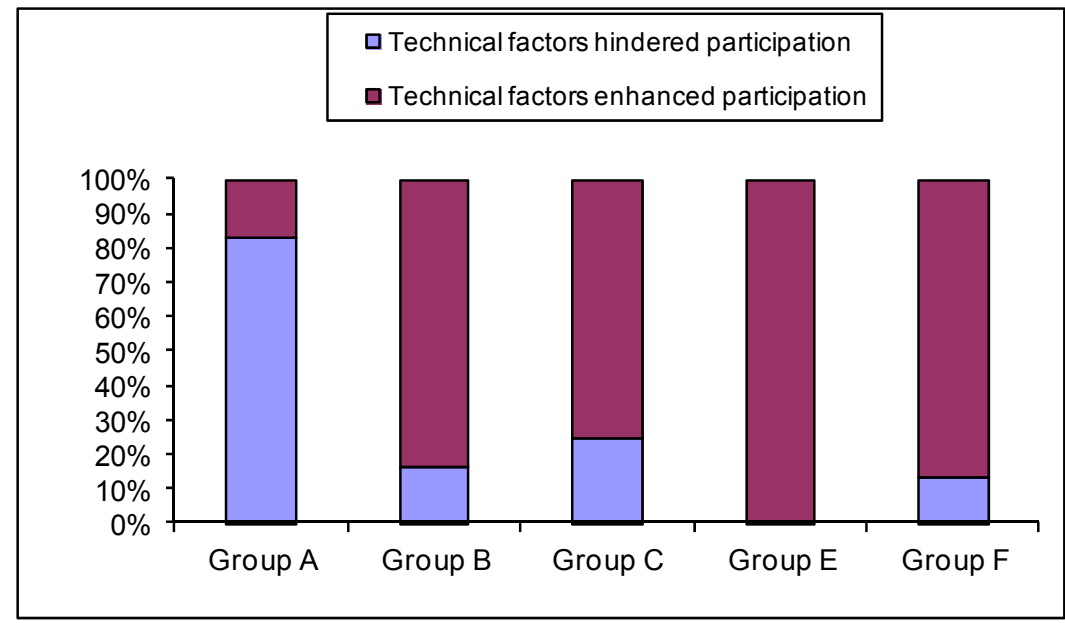

Figure 6 Summary of the analysis on technical factors hindering or enhancing participation for Groups A-F

Group A, in particular, reported that they had encountered quite a lot of problems regarding the use of web technologies, such as inaccessibility to e-learning platform, instability of the elearning services, and computers being affected by viruses. A selection of messages from Group A illustrating the technical factors that had hindered their participation is shown below:

- I have submitted the same reflective journals three times as I think there might be some problems relating to the operation of e-learn platform. Sorry! (GA-83-YYF)

- Sorry! I have to submit the reflective journal late as my computer at home is affected by virus, it's even worse that the computer I have borrowed from school is also contaminated with virus!!! (GA-85-WYL)

- I failed to logon e-learn platform this afternoon again. I am afraid that I may not be able to submit the assignment on time. Perhaps I can email it to Miss Ma first. (GA-155-KYL)

Luckily, these technical problems did not affect their level of participation as the problems could be resolved easily with the assistance of computer technicians.

\section{Discussion}

The Activity System framework (Engeström, 1987) is useful for bringing together a wide range of factors that impact on the learning activity. To align with the theoretical framework, the following attributes will be discussed based on the findings to examine how interactivity, social presence and teaching presence have contributed to effective social reflection in the CSCL community:

- Interactivity versus Critical reflective presence;

- Social presence versus Reflective and affective objectives;

- Teaching presence versus Critical reflective and social processes; and

- Role of technology in computer supported collaborative reflective dialogues. 


\section{Interactivity versus Critical Reflective Presence}

The analysis of participation levels indicated that the discussion forum was used often by most groups who contributed regularly. The debate was highly interactive as evidenced by the majority of direct responses and commentaries to messages, rather than postings of independent statements. The intra and intergroup discussion forum was used for social reflection, administration, and social and technical support. Findings also suggested that the quality of interaction significantly impacted on the quality of reflective understanding and interpretations co-constructed by the groups. Taking Group A and Group $\mathrm{C}$ as illustrative examples for discussion, there appeared to be a definite positive relationship between the quality of collaborative process within the groups and the quality of reflective thinking skills fostered.

With reference to Figure 2.1, it was found that Group A had posted the highest numbers of messages (162 valid messages).

Interactions among the members were intensive and rich as all of their messages were threaded, and more than $39.5 \%$ of the threaded messages had 3 to 12 referents, showing two to seven levels of discourse (Figure 2.6). Members of Group A verbally promoted each other's understanding through support, help and encouragement. It was common to observe that if a member of the group gave utterance to an idea or summarised a thought, her teammates would provide a cohesive explanation of interrelating ideas or clarify one's position on an issue, committing themselves to evaluate and assess that articulated ideas or beliefs in light of new information or experience sharing. Ensuring that each member of the group receives support that he

Furthermore, Group A participated actively in the collaborative reflective activities with even distribution of dialogue shared among members both in the intra and intergroup debate. Group A, as an effective activity system, successfully shared their reflective load which implied a flexible turn-taking and collaboration within the group. The depth, breadth, and spread of the postings among the Group A members indicated that there were high levels of social interaction and collaboration, contributing to the establishment of the community of reflective learners.

The quality interaction being generated and maintained within the learning community of Group A impacted significantly on their co-construction of new understanding and interpretations for transformative actions. Group A demonstrated they were most reflectively engaged in the intragroup dialogue with as high as $26.9 \%$ of the statements related to moral and ethical consideration of issues which was an indicator of a deep reflective process (Figure 3.3). With cohesive collaboration, critical peers could conduct dialogue and argumentations on multiple levels with inputs from wider perspectives. They worked collaboratively on a social and psychological analysis of issues, questioning the injustices of beliefs or practices. These processes spiralled into selfquestioning, taking into account others' views, recognising how prior experience and thoughts interacted with the production of one's own behaviour, and making sense of themselves and the world around them through a cooperative shared venture.

Group C, on the other hand, had a very different exchange pattern. They were second year fulltime student-teachers. It was reported that they posted the least number of messages (64 valid messages) (Figure 2.1) during the 5 week project, two and a half times fewer than those of Group A. Learners in Group C were not as engaged as Group A. Closer analysis of the discourse showed that personal points of view or external pieces of information group members presented went without any responses from other members of the group, or when members were challenged about their ideas, opinions or statements, they failed to frame a reflective response, indicating that there was very little group cohesion or reflective dialogue. Furthermore, most of the threaded messages identified in Group $\mathrm{C}$ were quite linear and showed poor interaction as more than a half of the discussion threads did not go deeper than level one discourse (Figure 2.8). 
Members of Group C involved in the reflective dialogue were quite passive. The intra and intergroup debates were unevenly distributed among the members with little sharing of the reflective process the task required. The depth, breadth and spread of the postings among the Group $\mathrm{C}$ members indicated low levels of social interaction and collaboration.

The scattered interaction generated within Group $\mathrm{C}$ severely affected the meaning negotiation and creation process of new understandings. More than $57 \%$ of their statements fell into Phase I of initial discussion of the issue, which was solid proof of a superficial reflective process taking place. Only $11.1 \%$ of their dialogue contributed to Phase III discussion which was half that of Group A (Figure 3.3). Reasons accounting for the lack of social interaction and critical reflection among the learners of Group $\mathrm{C}$ might be due to their perceptions of technology in promoting reflective dialogue, insufficient moderator invention or failure to establish an intrinsic rewarding reflective environment, which will be further explored in the coming sections.

\section{Social Presence versus Reflective and Affective Objectives}

Analysis of the levels of social interaction indicated that learning was taking place in a collegial and trustworthy environment for most groups in which participants had a sense of affiliation with each other and a sense of solidarity with the group.

A closer examination of the social instances, however, found a remarkably deviated pattern of social presence between Group A and $\mathrm{C}$, leading to different critical reflective and transformative outcomes (Figure 4). It was found that Group A posted a total of 160 social instances and posted the most interactive, cohesive and affective messages amongst all groups, indicating that reflective discourse was taking place in a supportive environment with a strong sense of group commitment. However, there were only 39 social instances identified in Group C, four times less than those of Group A. Amongst all groups, they posted the second lowest number of cohesive messages and the lowest number of affective messages. It was reported that Groups A, B, E and F posted messages intensively from the commencement of the project, indicating that their learners' collaboration had come to maturity after their first experience in CSCL. Group C was the exception as they were a newly formed group and a cohesive dimension emerged only after week 2 . It was surprising to find only 2 out of 39 social instances were affective ones, indicating that Group $\mathrm{C}$ would have had to collaborate in an environment with insufficient interpersonal support and encouragement being rendered by their peers.

The need for an environment of support and trust is important in encouraging honest and open reflection as reflective learning usually triggers a sense of discomfort and such emotional barriers may inhibit reflective learning if the frustrations are not acknowledged (Moon, 2001; Stewart \& Richardson, 2000). The findings suggested that the positive outcome of Group A in which they demonstrated deep reflection in the online debates, leading to co-creation of understanding and interpretations for transformative proposals, was directly related to the building of community among the learners. Strong feelings of community richly fostered their reflective processes which increased their reflective flow, sharing of reflective load, and engagement to the reflective tasks. Peers support and encouragement had created a safe self-revelation environment which promoted their openness to experience sharing, and their courage to challenge ideas and to confront the trusted others. A mutual trust and learning community had been well established in Group A during the first study which had greatly enhanced the critical reflective inquiry processes in the second study:

- We experienced on-line discussion in the previous textile module and were familiar with the operation. Good that a new member, Elisa has joined in our group and she has brought in new ideas and stimuli to the group dynamic. (GA-16-RJ-S1) 
- Every member could explicate their ideas and perspectives freely and we were able to receive peer's feedback openly. With intensive interaction in terms of questioning and giving responses, our critical reflective capabilities were promoted gradually. (GA-17-RJ-S2)

- Our group took the project seriously. Apart from on-line dialogue, we had about 6-7 hours face-to-face discussion a week to have tea-gathering and brainstorming. (GA-13-RJ-S1)

The failure to establish supportive relationships and strong group cohesion within Group C perhaps accounted for the surface reflection that took place. Rational argumentation within a group was the essential characteristic of critical reflection and it was important to learn how to handle confrontations with the critical peers in the social inquiry process or it might seriously affect the relationships and subsequently the collaborative reflective thinking processes among the group members as displayed in their intragroup discourse:

- I think good housewives are not their targets. The open and wild images being portrayed here make me believe that their main selling target is the slim and sexy lad y with lots of physical and psychological desire. (GC-17-YTL-I)

- I think the term 'good housewives' Anson had used is problematic... What do you mean by 'good housewives'? People buy things might not for their functional benefits...but for emotional satisfaction...even though 'good housewives' would have their desire... (GC-21-KYF-I)

- What I mean is the 'housewives in common sense'. It's true that everyone might have her/his desire, but I just want to point out these housewives are not the targets of these advertisements. (GC-24-YTL-I)

- I don't think 'housewives' are being excluded as the targets. Everybody wants to be praised as beautiful. 'Housewives' might buy these clothes to live up with the fashion body images regardless of their ages or body shapes. (GC-26-WKH-II)

- I want to make my point clear again that 'housewives' are not their main target, OK? (GC30-YTL-I)

Some members indicated their willingness to strive for improvement on their collaborative reflection in their reflective records but their inability to handle the conflicts in the group resulted in failure:

- Members were not actively involved in discussion, making the inquiry pace really slow??? Members should be self-disciplined and engaged in critical argumentation!!! (GC-13-RJ-S3)

- There were conflicts in the process of clarification of one's views. Hope that it would not affect our collaborative relationship. (GC-23-RJ-S3)

- We had to calm down and handle the confrontations rationally, making more space for improvement. (GC-24-RJ-S3)

It was clear that the establishment of unsatisfactory affective relationships ( 2 out of 39 social instances were affective ones) made Group C learners anxious and defensive and they were unwilling to take the risks involved in challenging their peers' ideas and beliefs which were further displayed in their lack of participation in the intergroup debate. Furthermore, lack of commitment was perceived as another main problem of Group C, which was highlighted in their reflective records, and hindered their social inquiry and reflective processes:

- It's natural that we need some time to warm up during the initial stage of exploration. I suggest that we should devote more time for discussion and communication. We have to summarize what we've on hand so far to improve our working efficiency. (GC-3-RJ-S1) 
- It's frustrating that no response was received for the posted messages and it's hard to come to conclusion for this discussion. (GC-9-RJ-S1)

- I suggest that everyone should try to provide more information to support her views. And each should try to take the leadership role in discussion. (GC-7-RJ-S3)

The importance of establishing a trustworthy environment for collaborative reflective discourse was further confirmed with participation in the intergroup debate. It was found that some learners who had taken a relatively active part in their intragroup discussion were relatively passive in the intergroup debate. It suggested that trust might not have been fully established within the intergroup community and some of them were not open enough to challenge views of peers with whom they had not worked with before. They may have perceived the intergroup forum as an untrustworthy environment and may have felt uncomfortable or threatened by open argumentations.

\section{Teaching Presence versus Critical Reflective and Social Processes}

Appropriate teaching presence was acknowledged as an important factor that might facilitate critical reflective skills to develop (Pilkington, 2003; Salmon, 2002b). The moderator role in a collaborative reflective community should adopt a noninterventionist approach, mainly introducing and summarising discussion and only intervening when there is a perceived specific need (Guldberg \& Pilkington, 2007). Eliminating the unnecessary hidden power relationships between facilitator and learners is the key to promote critical reflection.

In this study, the facilitator adopted a noninterventionist approach and made far fewer postings (31 messages) when compared with those in study one (90 messages) (Figure 5). This approach was made possible with the well-designed structured reflective tasks in which students were sufficiently prepared because the chosen issues were closely related to their practice and level of expertise. It was also due to the fact that their trust and collaboration had been successfully established in the first study:

- Emphasis had been put on making more in-depth reflection throughout the whole project so I think my capacity to make reflection was stronger this time. After studying peers' views, I would think it over first and if I did not agree with them, I would search for more literature to support my ideas. (GA-S2)

- Our first experience, just as what Carol said, had increased our mutual understanding, facilitating the collaborative reflective processes. (GA-SI)

The facilitator took the major role as the co-creator of a social environment to welcome and support students by addressing them by name and giving them positive feedback thereby helping them to feel that their contribution was valued, particularly in the beginning stages. In subsequent dialogues, the facilitator did not generally intervene in the discussion until summarizing at the close of discussion to provide formative feedback to review and comment students' contributions in constructive ways, and this was the case with Group A:

- During our online discussion, our lecturer had been following us very closely. Every week when we had submitted our reflective journal, our lecturer would send us an encouraging feedback saying that we had done a good job. When we got this piece of message we would be very happy to know that we were on the right track. This would highly motivate us to pay more effort on questioning the injustice practices the next time. (GA-S1)

- Our lecturer would give us supportive comments which had promoted my openness to others' views and capability to deepen the reflective processes. (GA-S3) 
The learners' positive comments in the focus group meeting suggest that an emotionally supportive and open facilitator has a positive impact on learners' collaborative reflective processes in which the validity of learners' experience was acknowledged and their sensitivity and courage to take part in reflection was fostered (Salmon, 2002a).

The facilitator apparently stayed in the background, while intervening in discussion only when needed. It was evident that the facilitator rendered the most support to Group $\mathrm{C}$ both in terms of the co-creator of a social environment and subject matter expert when the participants were found to be rather passive in taking part in the intragroup discussion. It was a pity that the facilitator missed the crucial time to step in when conflicts arose which led to an undesirable impact on their collaborative reflective processes in the later stage. Though it is important that the moderator should avoid the temptation to play down the learners' experience in any way or to counter it and enter into argument, the E-moderator should be alert to opportunities to comment, to help resolve learners' conflicts in the process of confrontation as confrontation was the key process in the critical social inquiry.

\section{Role of Technology in Computer Supported Collaborative Reflective Dialogues}

Overwhelmingly, most participants expressed that their experience with the use of technologies was positive. The findings showed that CSCL was capable of facilitating reflective discourse at a level which encouraged learners to collaboratively examine the taken-for-granted assumptions being perpetuated in fashion advertisements. Benefits of collaborating in the computer supported collaborative environment are summarised as follows: (a) to provide a way for learners to negotiate multiple and often contradictory positions, encouraging a dialectical encounter with others and a reflexive engagement with the self ;(b) to allow for contribution of their understandings on issues from any place and at any time that is personally convenient as multiple discussions often take place simultaneously; and(c) to obtain access to and periodic review of the permanent electronic transcript generated in this medium encourages reflection and promotes the synthesis of ideas. These benefits are evident in the following comments:

- Comparing the two experiences, we became much familiar with the online mode of learning which enhanced my ability in using IT. I learned how to utilize Blackboard in learning and I had no doubt that my critical thinking skill, communication skill, collaboration skill and selfmanagement capability had been improved. (GF-S4)

- I saw this as a learning opportunity for us. Even though we were in-service teachers for a few years, we might be subjective in many things. This mode of learning provided us a chance to reflect our perspectives on how we made judgments. (GA-S2)

Active engagement in the intergroup debate with satisfactory performance over the three phases of reflective processes was solid proof of the contributing role of technology in the computer supported collaborative dialogue which confirmed with findings of various studies on CSCL for reflective discourse (see for example, Hawkes \& Romiszowski, 2001; Heng \& Moor, 2003; Huynh, $2005)$. It was encouraging to note that as high as $33.9 \%$ of statements related to moral and ethical questioning of practices and beliefs, much higher than those being exhibited in the intragroup discourse (11\%-27\%) which suggested that deeper reflection was promoted by interpeer critique and debate within a wider community of knowledgeable peers that fostered greater diversities of perspectives.

Issues of reflective discourse taking place in network communication also prompted some insights on participant homo/heterogeneity. The advantages of diversity are numerous: new perspectives, experience, and contexts greatly enrich the reflective dialogue (Hawkes\& Romiszowski, 2001). Taking the full-time and mixed-mode learners of this study as an example, 
the professional experiences of full-time learners would have been limited to that obtained during periods within their degree programmes. The mixed-mode groups were by contrast studying parttime while still practicing their professional role as teachers. They would have been expected to have higher scores on the reflection and critical reflection scales than the undergraduate students. And this was exactly the case with deep reflective practices taking place in Group A and superficial reflective thinking processes identified in Group C.

Different performance over the processes of critical reflection between Group A and Group C was not only due to the group heterogeneity; their perceptions on the use of web technologies also seriously affected the group dynamics and thus the reflective practices. Although Group A had the most problems with the E-learning platform, they could overcome them and work confidently in the CSCL environment:

- We had encountered problem of submission failure, and could not open the file we submitted. Sometimes our school intranet might not function well or faced other limitations, which, unexpectedly, had enhanced our problem-solving skills. I think my peers are great. (GA-S4)

Group D, on the other hand, did not face much challenge in technical matters but their perceptions on the use of technology were quite different. Resistance to be collaborative online was identified as one of the strong factors leading to an undesirable outcome in the critical social inquiry process. This is evident in the following comments:

- Though we got no problem with the IT, I think face-to-face meeting is the best communication mode for us. (GC-7-RJ-S3)

- Personally, I believe that on-line discussion could be incomparable to face-to-face one in terms of effectiveness and efficiency. (GC-23-RJ-S3)

- Communication in written form was also a problem. Sometimes I thought written words might not be able to fully express what I wanted to say, so communication via telephone or meeting face-to-face maybe a better way for us. (GC-S3)

\section{Conclusion}

An analysis of the interrelationships among attributes of interactivity, social presence and teaching presence in this study indicated that they were important elements which might have contributed to or discouraged critical reflective argumentations in the CSCL community. Learners in general were positive with the use of technology to support their collaborative reflective dialogue in the technology-enhanced environment.

Findings confirmed that there was a strong relationship between the quality of collaborative process engaged in groups and the quality of critical reflective capabilities fostered. It was revealed that high levels of social interaction and collaboration contributed to the establishment of a community of reflective learners, nurturing a space for promoting higher critical reflective thinking through co-creation of new understandings and interpretations for transformative outcomes.

Findings suggested that high levels of social presence were necessary to support the deep reflection in an intrinsically rewarding environment. The affective roles played by the learners were found to be particularly significant in building the supportive and collegial interpersonal relationships to encourage honest and open argumentations in which confrontation was an essential feature of critical reflection.

The role of the e-moderator as the steering force to promote collaboration and reflection within the groups especially at the early stage of the learners' activities was revealed to be vital in this study. It is equally important for the facilitator to take a noninterventionist approach to eliminate potential power inequalities between the facilitator and learners, yet analysis assured that the im- 
portance of taking appropriate and prompt intervention to help resolve learners' conflicts arising of open argumentations should not be underestimated, as unresolved misunderstandings among learners would seriously affect the group dynamic and the social inquiry process.

This study suggested that Activity System Model as an investigative framework provides a useful tool for investigating collaborative learning processes enabled by web-enhanced activities. By applying this model to forum exchanges, it was possible to examine these collaborative learning processes from within the spaces. It was also possible, from coding the range and complexity of the postings to identify where some further developments to the model could be made.

The proposed analytical framework utilizing different content analysis models to reflect the nature of socio-cultural perspective was found to be useful for evaluating the quality of discourse in the CSCL discussion forum. Assessing the level and intensity of the participation provided a sense of how the participants were using the discussion forum. The analysis of the content of the discussion also contributed to the understanding on how the CSCL process had fostered the mastery of critical reflective capabilities.

In light of the methodological issues relating to coding reliability, limitations of the investigation in this study were summarized as follows:

- The current study was based on the earlier work of a number of researchers and it was not tested at the empirical level.

- The instruments used were built on small numbers of participants and limited numbers of messages and discussions over a short span of time.

- Coding process could be very tedious and time-consuming. Despite the fact that some qualitative analysis packages such as Atlas/ti ${ }^{\circledR}, \mathrm{NUD}^{*} \mathrm{IST}^{\circledR}$ and HyperQual ${ }^{\circledR}$ allow coding to be automated based upon multi-string text search and pattern matching, Chinese text with different linguistic structures may urgently require some sorts of innovations for computerized coding process.

\section{References}

Anderson, T., Rourke, L., Garrison, D. R., \& Archer, W. (2001). Assessing teaching presence in a computer conference context. Journal of Asynchronous Learning Networks, 5(2). Retrieved 18 May 2010 from http://www.aln.org/publications/jaln/v5n2/pdf/v5n2_anderson.pdf

Cole, M., \& Engeström, Y. (1993). A cultural-historical approach to distributed cognition. In G. Salomon (Ed.), Distributed cognitions: Psychological and educational considerations (p. 1-46). New York: Cambridge University Press.

De Wever, B., Schellens, T., Valcke, M., \& Van Keer H. (2006). Content analysis schemes to analyze transcripts of online asynchronous discussion groups: A review. Computers and Education, 46, 6-26.

Engeström, Y. (1987). Learning by expanding: An activity-theoretical approach to developmental research. Helsinki: Orienta-Konsultit.

Guldberg, K., \& Pilkington, R. (2007). Tutor roles in facilitating reflection on practice through online discussion. Educational Technology and Society, 10(1), 61-72.

Habermas, J. (1981). The theory of communicative action: Reason and the rationalisation of society. London: Heinemann Educational Books.

Hawkes, M., \& Romiszowski, A. (2001). Examining the reflective outcomes of asynchronous computermediated communication on in-service teacher development. Journal of Technology and Teacher Education 9(2), 285-308. 
Heng, M. S. H., \& Moor, A. (2003). From Habermas's communicative theory to practice on the internet. Info system Journal, 13, 331-352.

Henri, F. (1992). Computer conferencing and content analysis. In A. R. Kaye (Ed.), Collaborative learning through computer conferencing: The Najadan Papers (pp. 117-136). London: Springer-Verlag.

Hew, K. F., \& Cheung, W. S. (2003). Models to evaluate online learning communities of asynchronous discussion forums, Australian Journal of Educational Technology, 19(2), 241-259.

Hung, D., \& Wong, A. (2000). Activity theory as a framework for project work in learning environments. Educational Technology, 40(2), 33-37.

Huynh, M. (2005). Viewing e-learning productivity from the perspective of Habermas' cognitive interests theory. Journal of Electronic Commerce in Organizations for Review. (Special Issues on Social Aspects of E-Business), April-June, 33-45.

Leont'ev, A. N. (1978). Activity, consciousness, and personality. Englewood Cliffs, NJ: Prentice-Hall.

Ma, A. (2012). Determining learners' reflective levels and processes in a computer supported collaborative learning environment- $A$ case study of fashion consumerism. Manuscript submitted for publication.

Moon, J. (2001). PDP working paper 4: Reflection in higher education learning. UK: LTSN Generic Centre.

Pilkington, R. (2003). Reflecting on roles: Using synchronous CMC to develop a knowledge-building community amongst post-graduates. International Journal of Continuing Engineering Education and Life-long Learning, 13(3/4), 318-335.

Rourke, L., Anderson, T., Garrison, D. R., \& Archer, W. (1999). Assessing social presence in asynchronous text-based computer conferencing. Journal of Distance Education, 14, 51-70.

Salmon, G. (2002a). Mirror, mirror, on my screen...Exploring online reflections. British Journal of Educational Technology, 33(4), 379-391.

Salmon, G. (2002b). E-tivities: The key to active online learning. London: Kogan Page.

Stewart, S., \& Richardson, B. (2000). Reflection and its place in the curriculum on an undergraduate course: Should it be assessed? Assessment \& Evaluation in Higher Education, 25(4), 369-380.

Strijbos. J. W., Martens, R. L. Prins, F. J., \& Jochems, W. M. G. (2006). Content analysis: What are they talking about? Computers \& Education, 46, 29-48.

\section{Biography}

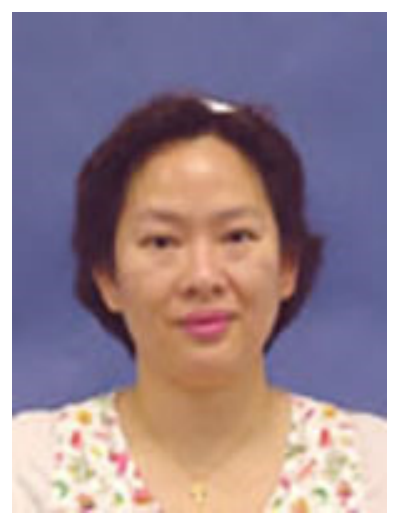

Dr. Ada Ma is the assistant professor of the Department of Health and Physical Education, at the Hong Kong Institute of Education. She is currently serving the Bachelor of Health Education (Honours) Programme as programme leader and teaching school health for both fulltime and part-time undergraduate and postgraduate programmes. She is interested in various research areas such as assessment, computersupported collaborative learning, school health, curriculum innovations, and lifelong learning. She has participated actively in various academic activities ranging from publication of conference proceedings, referred journal papers and book chapters to being a research investigator of internal and external funded projects, as well as a reviewer of various international referred journals. 